\title{
Modeling coupled convection and carbon dioxide injection for improved heat harvesting in geopressured geothermal reservoirs
}

\author{
Tatyana Plaksina ${ }^{1 *}$ and Christopher White ${ }^{2}$
}

*Correspondence: tatiana_ plaxina@yahoo.com

${ }^{1}$ Department of Petroleum Engineering, Texas A\&M

University, 907 Richardson Hall, College Station, TX

77843, USA

Full list of author information is available at the end of the article

\begin{abstract}
Geopressured geothermal saline aquifers are an abundant low-enthalpy geothermal energy resource available in many coastal regions including the US Gulf of Mexico. In such geographic areas thick geopressured sandstones (up to several hundred meters thick) hold tremendous geothermal heat with conservative estimates of gross extractable energy approximately $0.2 \mathrm{EJ}$ per cubic kilometer of the formation. Additionally, widespread geopressure in sedimentary deposits of the Gulf region preserves favorable petrophysical properties of unconsolidated sandstones such as high porosity and permeability, thus, enhancing productivity and economics of potential heat harvesting projects. In this study we investigate the potential of a typical geopressured reservoir in the US Gulf coast to deliver commercial quantities of geothermal heat with the possibility of simultaneous supercritical $\mathrm{CO}_{2}$ sequestration into the same formation. Specifically, we focus on numerical simulation study of heat extraction from a model based on the Camerina A sand of South Louisiana. In our numerical experiments, we consider both theoretical and practical implications of combining a traditional heat harvesting method with supercritical $\mathrm{CO}_{2}$ injection. Moreover, this study pays specific attention to the effect of natural convection due to the formation's tilt and uneven heating at the reservoir boundaries and its impact on the forced convection due to geofluid withdrawal. The numerical simulation results suggest that introduction of supercritical $\mathrm{CO}_{2}$ might have an observable positive effect on the ultimate heat recovery and that a strategic injection/production well placement might further enhance density-driven flows inside the geothermal formation.
\end{abstract}

Keywords: Geothermal energy, Geopressured brines, Saline aquifers, Natural convection, Forced convection, Carbon dioxide sequestration, TOUGH2

\section{Background}

Geothermal systems hold abundant and carbon-free thermal energy for potential electricity generation, space heating, and air-conditioning. For example, the subsurface potential of the US contains approximately $170,000 \mathrm{EJ}\left(1 \mathrm{EJ}=10^{18} \mathrm{~J}\right)$ of energy (MIT 2006). One such energy source readily available in many coastal regions across the globe is geopressured saline sedimentary aquifers. Geopressured aquifers are usually

\section{望 Springer}

(c) 2016 Plaksina and White. This article is distributed under the terms of the Creative Commons Attribution 4.0 International License (http://creativecommons.org/licenses/by/4.0/), which permits unrestricted use, distribution, and reproduction in any medium, provided you give appropriate credit to the original author(s) and the source, provide a link to the Creative Commons license, and indicate if changes were made. 
undercompacted, brine saturated, porous, and permeable sandstone formations that have anomalously high pore pressures and reservoir temperatures over $100{ }^{\circ} \mathrm{C}$. Among all geothermal systems, geopressured fields are considered a medium- and low-grade (or low-enthalpy) geothermal resource that occupies large subsurface areas in coastal regions (Esposito and Augustine 2011). The US states of Louisiana and Texas are examples of geographic locations where geopressured systems occur frequently and occupy the areal extent of more than $145,000 \mathrm{~km}^{2}$ (MIT 2006).

Several technical obstacles may render development of most coastal geopressured systems sub-commercial. These low-enthalpy systems require drilling multiple injection wells for improved heat sweep because they have lower heat content and thermal efficiency. Costly pressure maintenance programs and surface handling of withdrawn geofluids may make these reservoirs unattractive for commercial development (Freifeld et al. 2013). In addition to these problems, withdrawal of geothermal fluids might cause land subsidence due to compaction in the producing geologic formation unless the produced geofluid is re-injected into the reservoir or shallower formations (Gustavson and Kreitler 1979). As a result, pilot commercial projects exploit only those sites that have anomalously high geothermal gradients and strong water drives-the so-called "lowhanging fruit" of the tremendous resource.

In deep sedimentary basin geothermal production techniques are usually divided into two main categories: coproduced fluids and geopressured geothermal extraction. The first development strategy uses thermal energy of hot water coproduced with oil and gas. This type of geothermal resource is confined to existing hydrocarbon fields at depths between 4 and $6 \mathrm{~km}$ (MIT 2006). In the US, the annual volume for coproduced hot water is approximately 33 billion barrels which is equivalent to $3000 \mathrm{MW}$ based on geofluid temperature of $100{ }^{\circ} \mathrm{C}$ (Curtice and Dalrymple 2004). Geothermal projects of the second category, geopressured brines, are independent from oil and gas production and develop thermal potential of deeply buried aquifers. According to the latest conservative estimates, the Northern Gulf of Mexico (GOM) basin stores raw thermal energy of about 46,000 EJ (White and Williams 1975).

Although coproduced and independent geothermal reservoirs seem to be very similar for modeling purposes, their initial states (and thus, model initialization methods) differ. This research demonstrates benefits of initializing numerical models as quiescent systems with a proper temperature distribution (quiescent period is a period during which the reservoir experiences no injection or production, and it might range from 100 to millions of years). The thermal profile of coproduced geothermal reservoirs, however, is distorted by oil and gas production, and initialization with the quiescent period would not provide the correct temperature distribution for a coproduced project. This study focuses on geopressured brines, and therefore, we assume no forced convection (due to injection or withdrawal of geofluid) prior to heat harvesting.

Despite the fact that geothermal heat extraction is still considered a marginally profitable energy industry, a number of scientists have already proposed several strategies to make geothermal projects more economically attractive. More specifically, Ganjdanesh et al. (2015) have investigated how the energy cost could be reduced with capturing and storing $\mathrm{CO}_{2}$ inside the geothermal formation. National agencies such as the US Geological Survey (USGS) and Department of Energy (DoE) also propose favorable conditions 
and location for such project that include vast subsurface areas of the GOM (Warwick et al. 2014; Goodman et al. 2011; Nicot 2008). Several prominent studies have proposed to utilize sequestered $\mathrm{CO}_{2}$ as a secondary fluid to deliver the heat from reservoir's hot lower boundary (Randolph and Saar 2011; Salimi and Wolf 2012; Randolph et al. 2013; Adams et al. 2014). This interest in using $\mathrm{CO}_{2}$ in geothermal projects stimulated further research on the behavior of the supercritical greenhouse gas in the subsurface conditions. In this context, for our investigation the most interesting works on $\mathrm{CO}_{2}$ behavior in geologic formations include the numerical study of $\mathrm{CO}_{2}$ flow under non-isothermal conditions by Singh et al. (2011), the investigation of supercritical $\mathrm{CO}_{2}$ injection into a deep saline aquifer by Vilarrasa et al. (2013), and the study of the dynamics inside the $\mathrm{CO}_{2}$ geologic storage by Pool et al. (2013). All these works provide a solid foundation and expectation of how supercritical $\mathrm{CO}_{2}$ plume should behave inside a geothermal system.

This study builds on this foundation and offers an investigation of a new method for improved heat recovery from low-enthalpy geopressured aquifers by combining the effects of natural and forced convection and density-driven effects of $\mathrm{CO}_{2}$ injection. Particularly, we demonstrate the advantages of characterizing a natural convection pattern inside a tilted or flat geothermal formation that might help place injection/production wells strategically to enhance subsequent heat extraction by the coupled convection. This approach allows for better geothermal resource estimation, potentially improved economics and a selection of a more efficient production arrangement. Because the current study might be particularly beneficial to the US GOM region, in our numerical experiments we use models with petrophysical and thermodynamic properties of typical GOM geopressured formations. Additionally, this study discusses heat harvesting simultaneous with small scale $\mathrm{CO}_{2}$ sequestration, the way to avoid land subsidence with re-injection of the produced geofluid into the same formation and the effect of the formation dip on the ultimate heat recovery. One South Louisiana aquifer, the Camerina A, is a central example for this study used for a more detailed investigation of an optimal geothermal production scenario.

Although the economic feasibility evaluation is not a part of this study, because of constant changes in the carbon tax agenda, high volatility on energy markets, and varying abilities to fund renewable projects, we can outline a possible life cycle of such geothermal reservoir for engineering and energy production purposes. A geopressured reservoir could be brought down to pressure suitable for economic injection of the supercritical gas (like in the case of Camerina reservoir the upper portion of which has been depleted during oil production). However, to prevent quick subsidence of mostly unconsolidated sediments, the geofluid must be re-injected into the shallower layers. At this stage of the production cycle both thermal and dynamic energy can be used for electricity generation purposes. Once overpressure is depleted, the project can be categorized as a carbon dioxide sequestration project and corresponding financial benefits can be applied to offset high compression costs. However, at this point in the life cycle all withdrawn geofluids must be returned into the formation after heat harvesting to maintain reservoir pressure and help mixing the supercritical gas with the brine. In addition to creating density-driven convection, this mixing is important in controlling the gas plume and 
ensure caprock integrity as discussed later (Islam et al. 2013; Shukla et al. 2010; Karimnezhad et al. 2014; Wang et al. 2015).

\section{Methods}

In this section we introduce necessary theoretical background on convection in flat and tilted porous media which are analogous to brine saturated sandstone geothermal reservoirs used in this study as well as describe the numerical simulation model used to obtain thermal energy production data. Additionally, we provide the description of the model initialization process and the design of experiment that helps identify the most significant parameters affecting the energy output.

\section{Convection in flat and inclined porous media}

Natural convection may occur in a fluid-saturated porous medium subjected to nonuniform heating. The Rayleigh number describes the energy and mass transfer (Horne 1975).

$$
R a=\frac{k \rho^{2} c \gamma \Delta T g h}{\mu K}
$$

In Eq. $1, \gamma$ is the thermal expansivity of the fluid, $\rho$ is fluid's density, $k$ is permeability of the porous medium, $g$ is the acceleration due gravity, $c$ is fluid's specific heat, $h$ is the height of the system's square cross-section, $\Delta T$ is a change in temperature, $\mu$ is the fluid's viscosity, and $K$ is the average thermal conductivity of the fluid and the rock matrix. The value of the Rayleigh number indicates if conditions favorable for convection have been reached. Specifically, when $R a$ exceeds $4 \pi^{2}$ due to non-uniform heating and/or compositional heterogeneities (for instance, changes caused by mixing with gas or salt), the investigated system becomes unstable and convection cells begin to form (the critical value of $4 \pi^{2}$ is derived from a solution for a system with an infinite horizontal dimensions, uniform petrophysical properties, and constant top and bottom temperatures (Nield and Bejan 2006)). Based on the same study, a typical fluid density change in naturally convecting systems is about one percent.

Although convection in flat systems is of interest in some development cases as highlighted in Zhang et al. (2014), in the GOM region many hot saline aquifers are dipping. Dip in such geologic formations can be local or sustained for the entire length of the reservoir. Tilted geopressured formations are particularly common around salt structures that cause deformation of adjacent sand deposits as well as their anomalously high temperature. The base case of this study, the Camerina A sand, is a dipping system due to its proximity to the Gueydan salt dome (Smith and Reeve 1970). Therefore, a more careful examination of natural convection in inclined reservoirs is needed.

For tilted systems a modified definition of the Rayleigh number can be used as in Eq. 2 (Nield and Bejan 2006):

$$
R a=\frac{k \rho^{2} c \gamma \Delta T g L \sin \theta}{\mu K}
$$

Here the height of the system $h$ is replaced by the length multiplied by sine of the dip $L \sin \theta$. This subtle change in the formula also affects calculation of the critical Rayleigh 
number. For inclined systems it becomes $4 \pi^{2} \sin \theta$ implying that in dipping reservoirs convection starts to dominate conduction at relatively small $R a$ values (Nield and Bejan 2006). Apart from the reservoir dip and non-uniform heating, salt dissolution and precipitation have been found to promote thermohaline convection in GOM sediments (Hanor 1987).

\section{Simulation model and setup of numerical experiments}

The Northern GOM basin is a prolific geopressured geothermal province with many thick sandstone saline aquifers. To build a realistic numerical model for subsequent flow simulations, we use the properties of a hot saline aquifer in the GOM coast of Louisiana suitable for heat extraction. The Camerina A sand of South Louisiana is selected as a prototype for the simulation model (Plaksina 2011; Gray 2010).

The Camerina A sand is a Late Oligocene deposit identified near the Gueydan salt dome in Vermillion Parish, LA (Fig. 1) at an approximate true vertical depth of $4300 \mathrm{~m}$

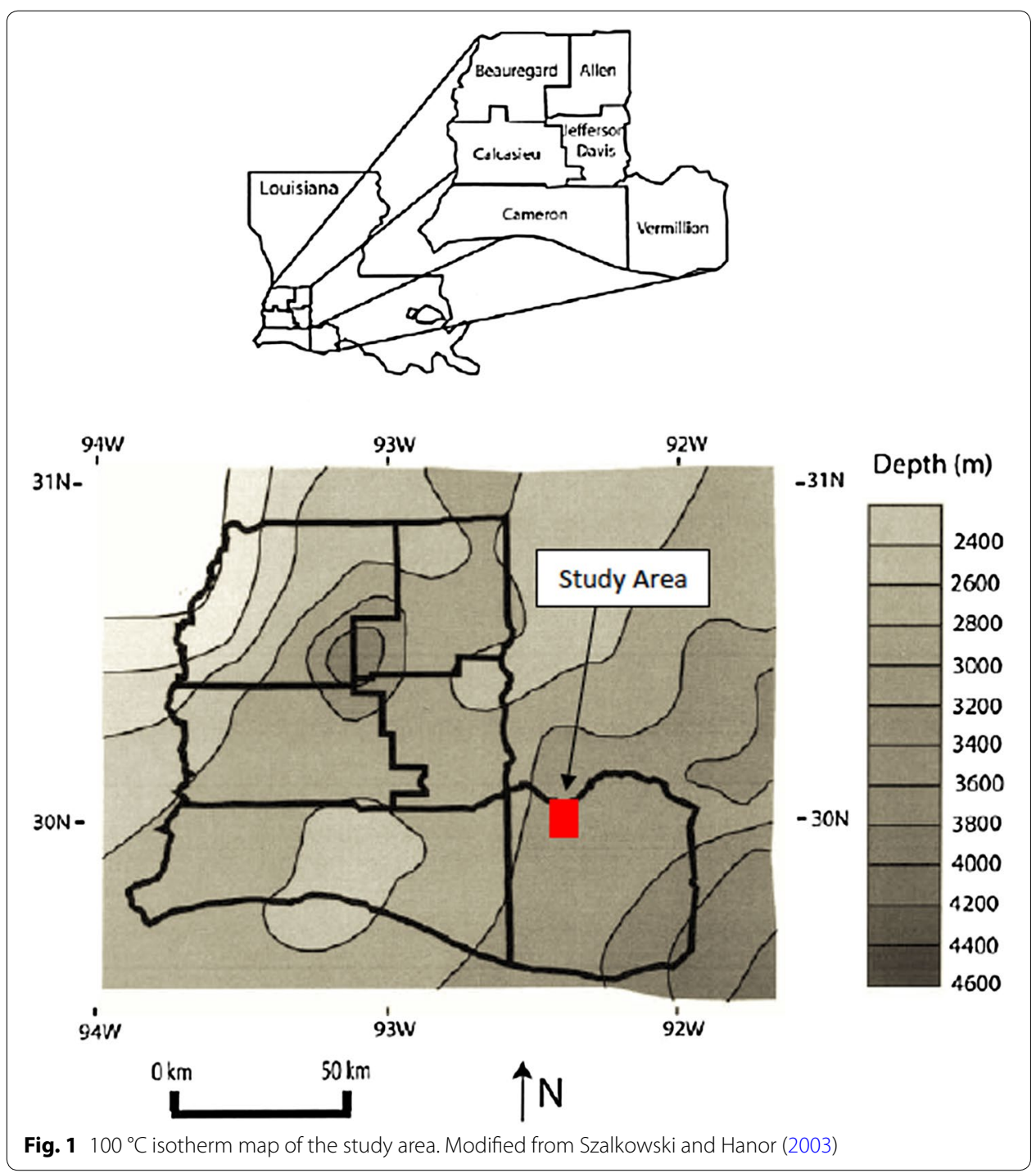


(Gray 2010). Its depositional environment is a delta front to distributary mouth bar and it is a part of a marine transgressive sequence. The sand's average thickness is approximately $100 \mathrm{~m}$, permeability is approximately $200 \mathrm{md}$, and its porosity varies between 9-31 percent. The Camerina $\mathrm{A}$ sand is a dipping aquifer with varying dips ranging between $1.2-28^{\circ}$. The corrected formation temperature is approximately $140{ }^{\circ} \mathrm{C}$ with a geothermal gradient of approximately $29^{\circ} \mathrm{C} / \mathrm{km}$ and estimated formation pressure is over $80 \mathrm{MPa}$ (Gray 2010). Other relevant properties used for 2D TOUGH2 simulations are summarized in Table 1. The sand formation has all properties relevant to the objectives of this study such as dip, anomalously high formation temperature suitable for electricity generation, substantial thickness, and areal extent. Therefore, its properties can be used for the base case simulation model in our investigation of an optimal heat harvesting scenario with zero mass net withdrawal.

Although surface facilities and energy conversion is not in the scope of this study, it is important to note that the Camerina A sand is located in a geographic area where relatively low geothermal gradients are expected. Thus, one of possible methods to convert the heat energy of the aquifer's fluid into electricity is an organic binary cycle for electricity generation (MIT 2006).

\section{Model initialization and design of experiments}

To see the benefits of initializing geomodels with proper geothermal gradient and running the quiescent period, a number of $2 \mathrm{D}$ simulations were performed with varying geometries and petrophysical properties (Pruess et al. 1999). Because one of the objectives of this study is to find parameters that influence heat recovery the most, a factorial design was used to vary the factors of interest, and for each case the Rayleigh number and its critical value were calculated (tabulated in Additional file 1: Appendix B). To encompass a wide range of geometric and petrophysical properties found in the Northern GOM basin, two levels of permeability (100 and $1000 \mathrm{md}$ ) and thickness (100 and $200 \mathrm{~m})$, and three levels of dip (0, 2 and $\left.15^{\circ}\right)$ were used in the design of experiments (Ewing et al. 1984).

All simulation models have three layers of rock: the top and the bottom ones are impermeable bounding layers with infinite heat capacity to imitate multiple formations

Table 1 Reservoir properties for 2D simulation runs

\begin{tabular}{lll}
\hline Property & Value & Units \\
\hline Initial pressure & $3.45 \times 10^{7}$ & $\mathrm{~Pa}$ \\
Initial average temperature & 135 & ${ }^{\circ} \mathrm{C}$ \\
Porosity & 0.20 & - \\
Matrix compressibility & $2.0 \times 10^{-8}$ & $1 / \mathrm{Pa}$ \\
Injection water enthalpy & $3.0 \times 10^{5}$ & $\mathrm{~J} / \mathrm{kg}$ \\
Rock density & 2600 & $\mathrm{~kg} / \mathrm{m}^{3}$ \\
Wet rock heat conductivity & 2.0 & $\mathrm{~W} / \mathrm{m}^{\circ} \mathrm{C}$ \\
Reservoir length & 4000 & $\mathrm{~m}$ \\
Reservoir width for 2D run & 100 & $\mathrm{~m}$ \\
Salinity & 0 & $\mathrm{ppt}$ \\
Geothermal gradient & 29 & ${ }^{\circ} \mathrm{C} / \mathrm{km}$ \\
\hline
\end{tabular}


with constant temperatures above and below the reservoir and the middle layer is the permeable sandstone reservoir (Fig. 2). An initialization script assigns temperature value to each grid block (including those of the bounding layers) according to the chosen geothermal gradient (e.g., the gradient of the Camerina A sand). Although salinity (or more generally, composition) is another factor that might influence convection and, thus, the ultimate heat recovery, in this study we focus exclusively on significance of geometric parameters of the geologic system and rock properties (Hanor 1987).

The formation pressure and geothermal gradient (Table 1) are lower than they would be expected in the geopressured zone in the GOM coast. Gray (2010) suggests that the Camerina A sand, which is a typical sand deposit in the zone, has a geothermal gradient of $29^{\circ} \mathrm{C} / \mathrm{km}$ and initial formation pressure over $80 \mathrm{MPa}$. In our numerical investigation, however, the value of the initial formation pressure is lowered for two reasons. First, the solutions obtained with the equation of state (EWASG) in the simulator of choice (TOUGH2) become less stable and reliable at high pressures. To our knowledge, this numerical problem has not been solved to date, thus, these extreme pressure conditions are still out of numerical reach even though the researchers are on track to address this problem for extra deep reservoirs (Zhang et al. 2011). Because of this gap in current numerical tools, we decided to resort to a common in such situation approach and work in the range of pressures that provide reliable solutions. Nevertheless, we emphasize that the actual reservoirs of such temperatures and pressures are found much deeper. Second, we conduct a comparative study of production cases with and without $\mathrm{CO}_{2}$ injection to analyze the effect of density-driven convection. To achieve this, it is instrumental to keep the numerical test conditions as similar as possible. However, at high initial pressures which become even higher, downdip simulation of $\mathrm{CO}_{2}$ injection with current software tools is impossible for reasonable injection pressure range. Thus, to compare energy output from the simulated systems in which only $\mathrm{CO}_{2}$ injection rate is varying $(0$

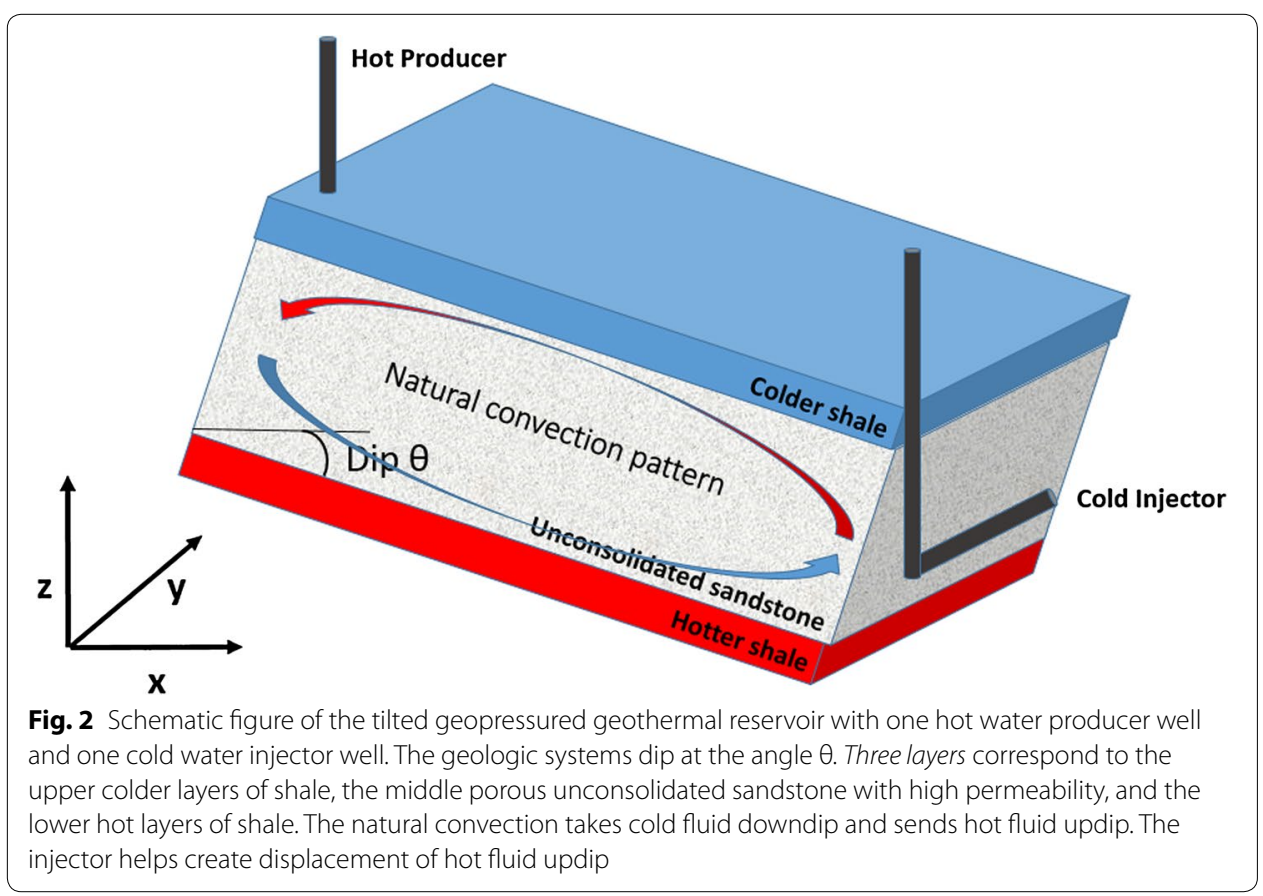


for no $\mathrm{CO}_{2}$ injection and $10^{-4} \mathrm{~kg} / \mathrm{s}$ for the case with $\mathrm{CO}_{2}$ injection), the initial formation pressure is kept at $34.5 \mathrm{MPa}$. This pressure value was derived from the experiments with the simulator and the range of stability of the equation of state.

As for the land subsidence problem usually associated with geothermal development, we propose to re-inject the withdrawn geofluid into the same formation (in the case of extreme overpressure, however, injection into a shallower formation might be considered at the initial production stage). This strategy is common place for geothermal projects because it helps solve several problems. First, keeping net zero withdrawal prevents compaction of the unconsolidated sandstone and preserves favorable petrophysical properties. Second, cold water re-injection is an important component in setting the forced convection in motion and keeping the supercritical gas plume from rising toward the top of the reservoir. Final, re-injection of the geofluid back into the formation relieves some costs associated with surface handling of large volumes of geothermal fluids (MIT 2006).

The final aspect of the modeling process that is essential for understanding the dynamics of the simulated system is the production arrangement with a $\mathrm{CO}_{2}$ injection well. Schematic Fig. 3 shows that the design with the $\mathrm{CO}_{2}$ well is slightly different from that without $\mathrm{CO}_{2}$ injection. Because caprock integrity is one of the biggest concerns in any $\mathrm{CO}_{2}$ sequestration project, we disperse the gas plume by placing the $\mathrm{CO}_{2}$ injection well at bottom of the reservoir at approximately middle of the model. This arrangement allows us to keep the supercritical gas sufficiently far away from the hot water producer and sufficiently close to the descending cold water front from the cold water injector. As Anchliya (2009) demonstrated, strategic placement of injection wells allows to dynamically control the process of $\mathrm{CO}_{2}$ sequestration and ensure the gas plume containment

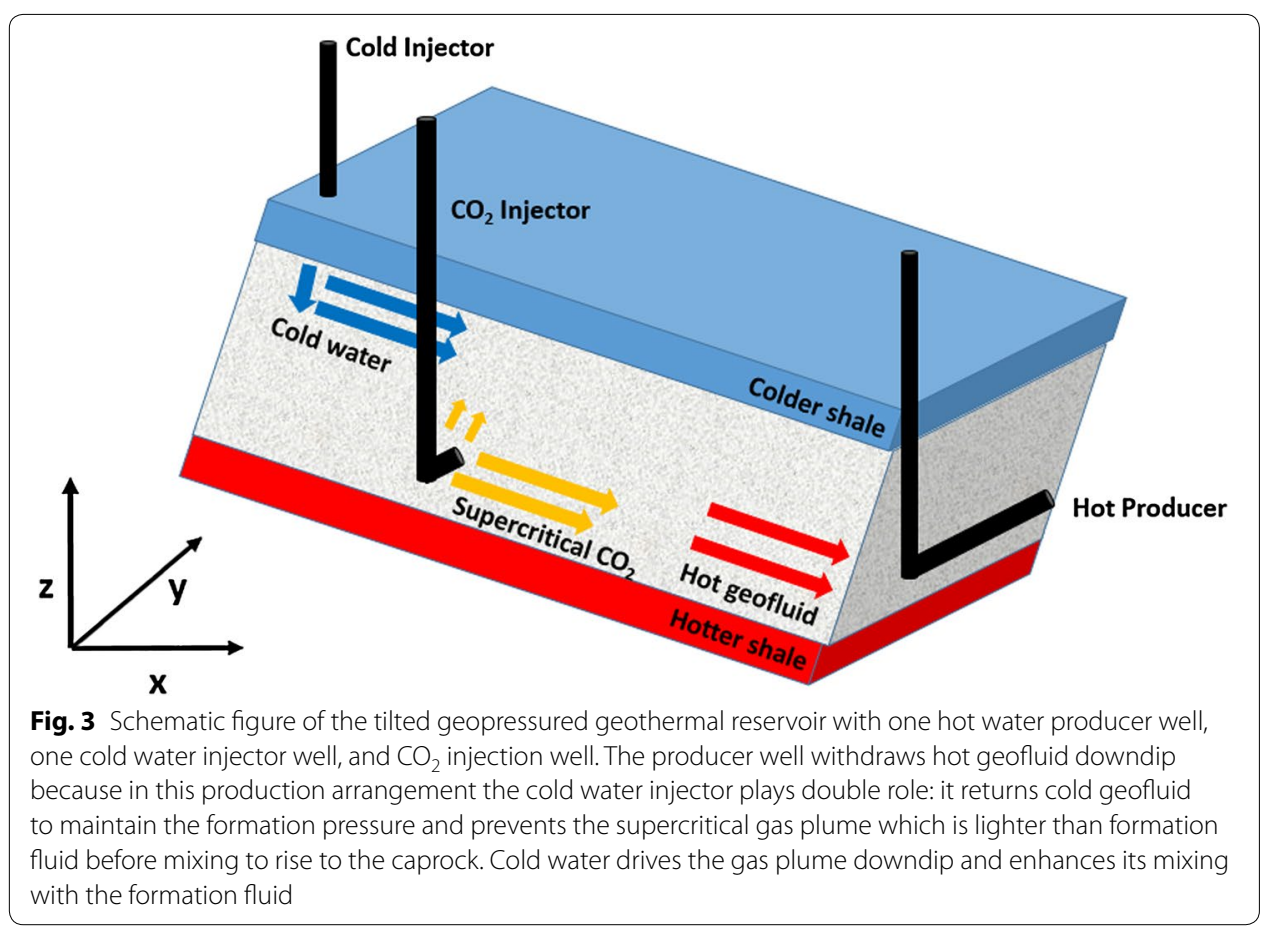


within the reservoir. It also helps maintain the integrity of the caprock because only small concentrations of the supercritical gas eventually rise to the top of the reservoir.

\section{Results}

\section{Natural convection modeling}

The ability to predict heat transport (such as conduction or convection) is valuable for successful production planning, but not sufficient for adequate geothermal resource estimation and developing an optimal production strategy. In addition to the Rayleigh number, the engineer needs to know the approximate shape of the natural convection pattern, the span of the quiescent period during which natural convection stabilizes, and the effect of the bounding layers on the reservoir's temperature profile. This section provides the results of modeling these three aspects.

Nield and Bejan (2006) outline problems with computing and examining convection patterns in inclined porous media and conclude that in general tilted systems tend to have unicellular convection pattern until very high $R a$ are achieved. A coarse grid simulation with the properties listed in Table 1 reveals a kilometer-scale natural convection loop, with hot fluid being convected along the top of the reservoir (Fig. 4). Another important aspect in characterization of natural convection is duration of the quiescent period during which a geothermal system reaches stable temperature distribution. For computational efficiency, the quiescent period should be the shortest time span after which no significant change in the convection pattern occurs. To establish this time period, we consider cases with moderate $R a$ 's and estimate the time span after which the temperature and aqueous phase flow in each grid block change negligibly. Cases two and eight from the experimental design (Additional file 1: Appendix B) are suitable for this

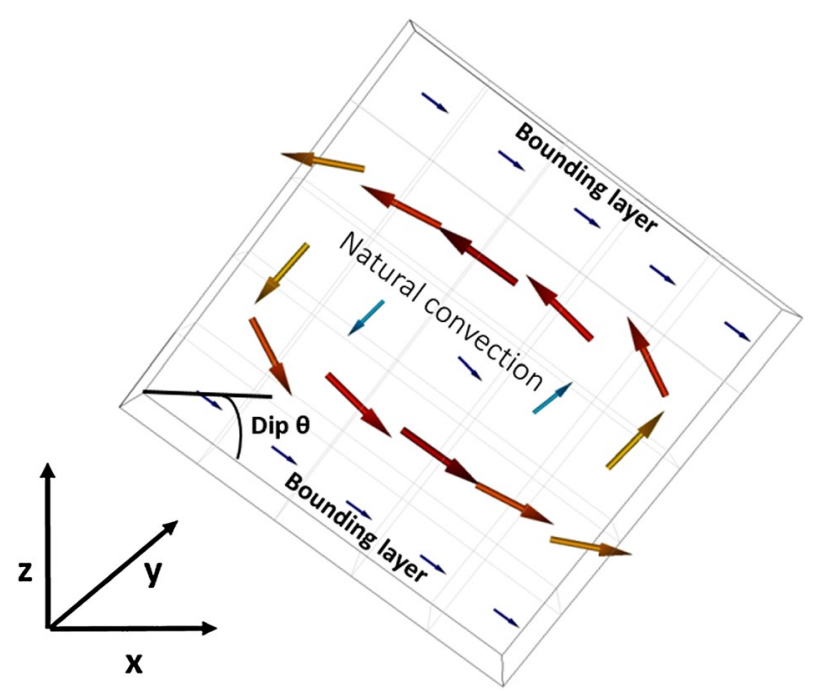

Fig. 4 Vector plot of aqueous phase flow $(\mathrm{kg} / \mathrm{s}$ ) for $5 \times 1 \times 5$ blocks $(500 \mathrm{~m}$ in $x$-direction, $100 \mathrm{~m}$ in $y$-direction, and $500 \mathrm{~m}$ in $\mathrm{z}$-direction) model dipping at $45^{\circ}$ with top and bottom bounding layers of infinite heat capacity. Pattern snapshot is taken after 1000 years of quiescent period, modeled in TOUGH2, and visualized with PetraSim software. Heat is conducted into the bounding layers high in the reservoir, and into the reservoir at greater depths. Length and color of the vectors reflect the magnitude of mass transfer. The range is from short vectors with cold colors to long ones with warm colors. For this image, the range is from 0 to $0.00003 \mathrm{~kg} / \mathrm{s}$ 
analysis and were run for 1 million years as quiescent systems. Additional file 1: Appendix $C$ provides details of how the quiescent period of 1000 years is obtained with available software tools. Because the mean of difference of aqueous phase flow values between 1000 and 10,000 years comprise less than 0.1 percent of the mean of initial aqueous phase flow values in both cases, the change after 1000 years is not significant and can be neglected. We get the same results if we consider temperature instead of aqueous phase flow. These results are omitted for brevity.

To demonstrate how the natural convection pattern stabilizes, the previously used coarse model with $5 \times 1 \times 5$ grid blocks ( 5 grid blocks in the $x$-direction, 1 grid block in the $y$-direction, and 5 grid blocks in the $z$-direction with each grid block having dimensions of $500 \mathrm{~m} \times 100 \mathrm{~m} \times 500 \mathrm{~m}$ ) is kept quiescent for 1 million years. Comparison of vector plots of aqueous phase flow after $1 \mathrm{~s}, 1000$ years, and 1 million years show little visual or quantitative difference after 1000 years (Fig. 5).

The final aspect of natural convection modeling that requires discussion in this section is the effect of the bounding layers on the reservoir's temperature profile. Impermeable colder top and hotter bottom bounding layers with infinite (or very large) rock heat capacity simulate low layers permeability (for instance, shale) that allow heat, but not mass transfer in and out of the reservoir. The bounding layers with large heat capacity supply the porous medium with constant heat fluxes that produce evenly spaced contour lines in the temperature profile (Fig. 6). After 1000 years quiescent period, temperature contours appear nearly horizontal (without vertical exaggeration shown on the figures), and their slight curvature is due to natural convection in the reservoir's geofluid (Fig. 7). When the bounding layers are not included, and the model is run for the same quiescent period of 1000 years, the range of temperatures decreases, and with lesser natural convection, the temperature contours are nearly planar and simpler in structure (Fig. 8).

Even though the reservoir has uniform petrophysical properties, the range of temperatures without bounding layers is 6 percent less than in the previous case and the contours are not equally spaced. Because the bounding layers give a wider, evenly spaced, and more realistic temperature profile (realistic in a sense that any GOM geopressured aquifer is bound by other formations that conduct heat in and out of the reservoir), all production cases discussed below are initialized and kept quiescent for 1000 years. The last illustration in this section (Fig. 9) shows the interdependence of the Rayleigh number and variance of temperature with time. The plot confirms that the systems with high $R a$ have higher variability in temperatures due to more vigorous convection and that stabilization time for the geomodels with uniform properties is relatively short. Because the graph has nearly horizontal trend (in other words, additional 10-, 100-, etc., fold increases in quiescent time do not change the temperature distribution), 1000 years is sufficient duration for the quiescent period.

\section{Geothermal production and $\mathrm{CO}_{2}$ injection modeling}

Using the experimental design (Additional file 1: Appendix B), we generated three sets of simulations: (1) twelve geofluid production cases initialized without the proper geothermal gradient and quiescent period, (2) twelve geofluid production cases with natural convection in-place at the time of heat extraction, and (3) a set of twelve cases with simultaneous geofluid production and $\mathrm{CO}_{2}$ injection, initialized with natural convection. 


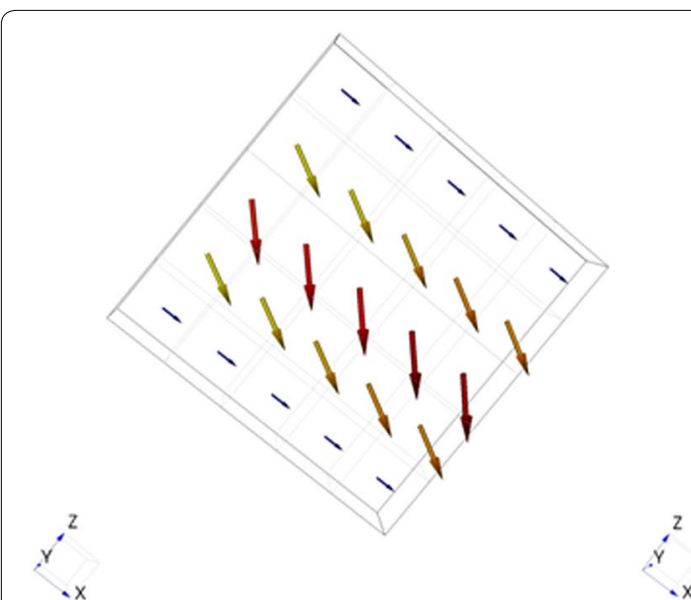

a 1 second.

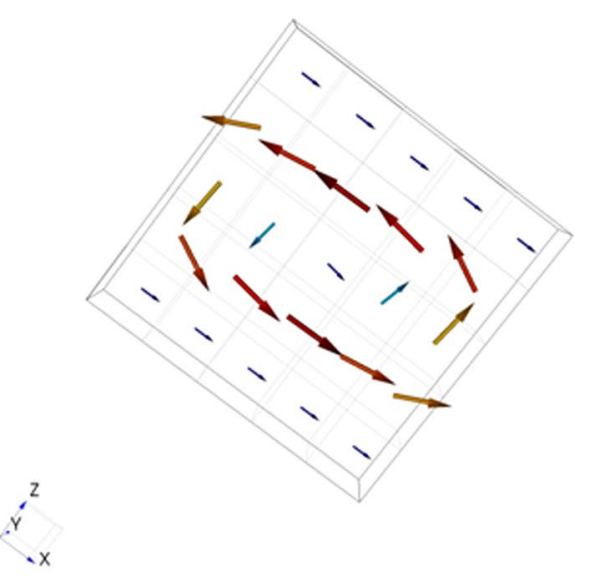

b 1,000 years.

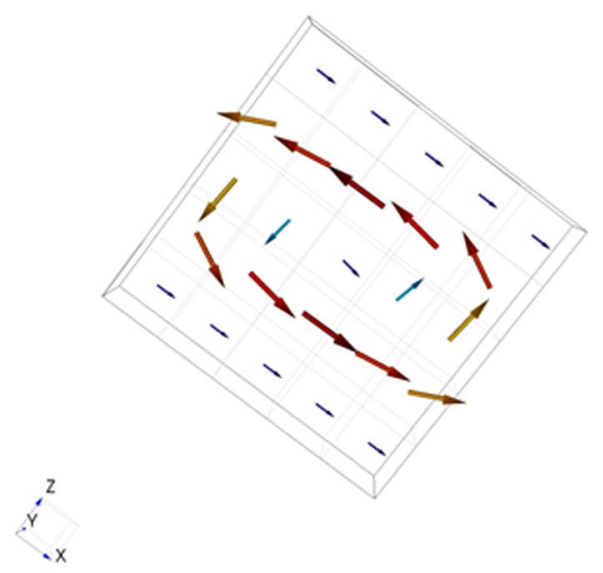

c 1 million years.

Fig. 5 Vector plots of aqueous phase flow $(\mathrm{kg} / \mathrm{s})$ for a model with $5 \times 1 \times 5$ blocks $(500 \mathrm{~m}$ in the $x$-direction, $100 \mathrm{~m}$ in the $y$-direction, and $500 \mathrm{~m}$ in the $z$-direction) with top and bottom bounding layers of infinite heat capacity. Pattern snapshots are taken after a 1 second, b 1000 years, and $\mathbf{c} 1$ million years of the quiescent period. Visually the pattern stabilizes after 1000 years

The response of interest for all simulation runs is energy extracted, $E$, after 10,20 , and 30 years of production. These results along with the factors are merged into one dataset and imported into statistical modeling software (R Team 2013).

To focus on the most important factors, the dataset is split into subsets by time (10, $20,30$ years $)$ and flow rates $(0.2,2,20 \mathrm{~kg} / \mathrm{s})$ and inspected for correlation. Correlations between energy outputs for 10 and 20 years of production and 20 and 30 years of production are 0.999 and 0.998 , respectively. Correlations between subsets split by the production flow rate are 0.999 and 0.997 for $0.2-2 \mathrm{~kg} / \mathrm{s}$ and $2-20 \mathrm{~kg} / \mathrm{s}$, respectively. Therefore, it is possible to reduce the number of factors by analyzing only one subset with energy output after 10 years of hot water production at a flow rate of $0.2 \mathrm{~kg} / \mathrm{s}$. All significant factors found for this subset are significant for the entire dataset. 

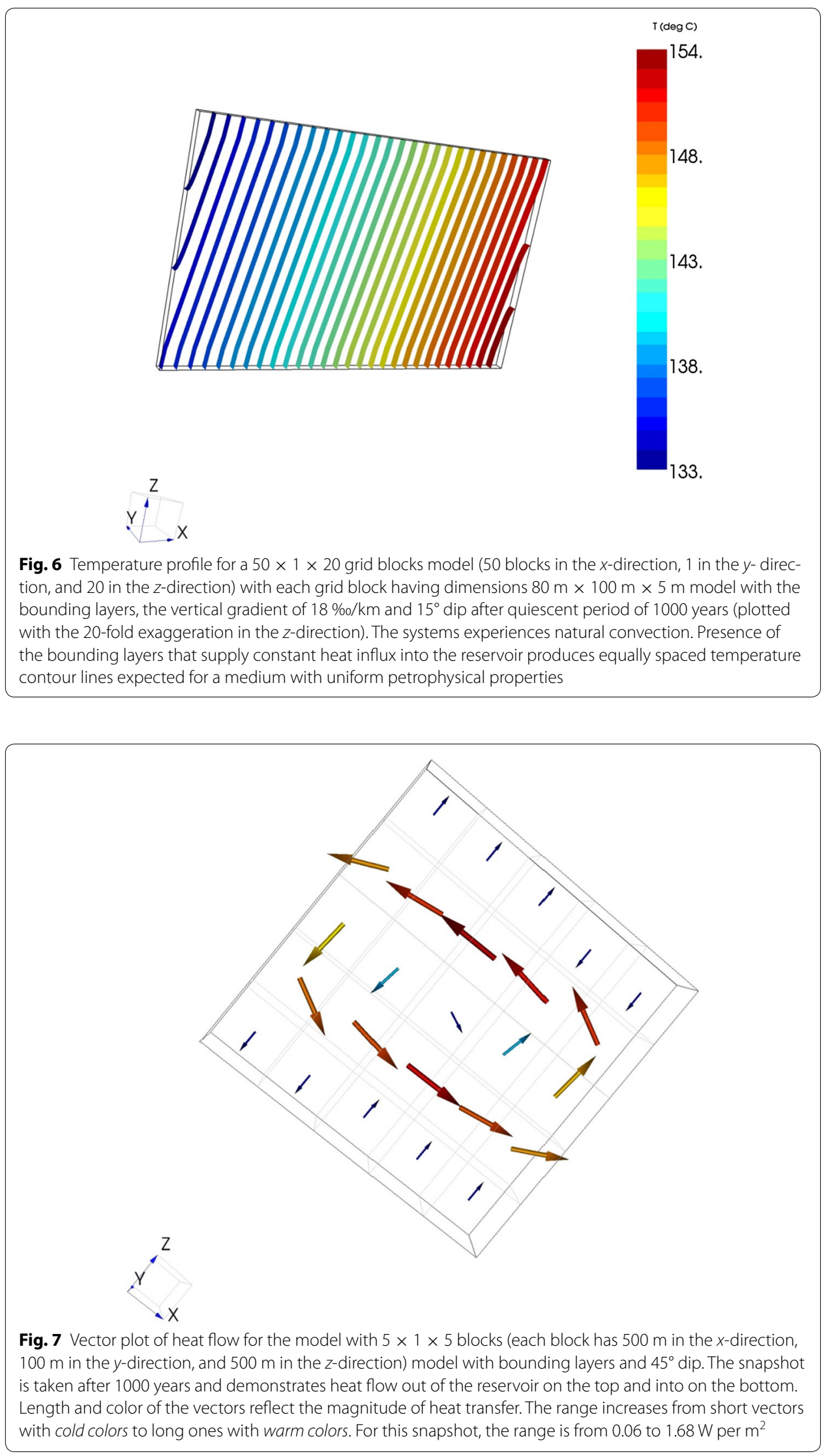

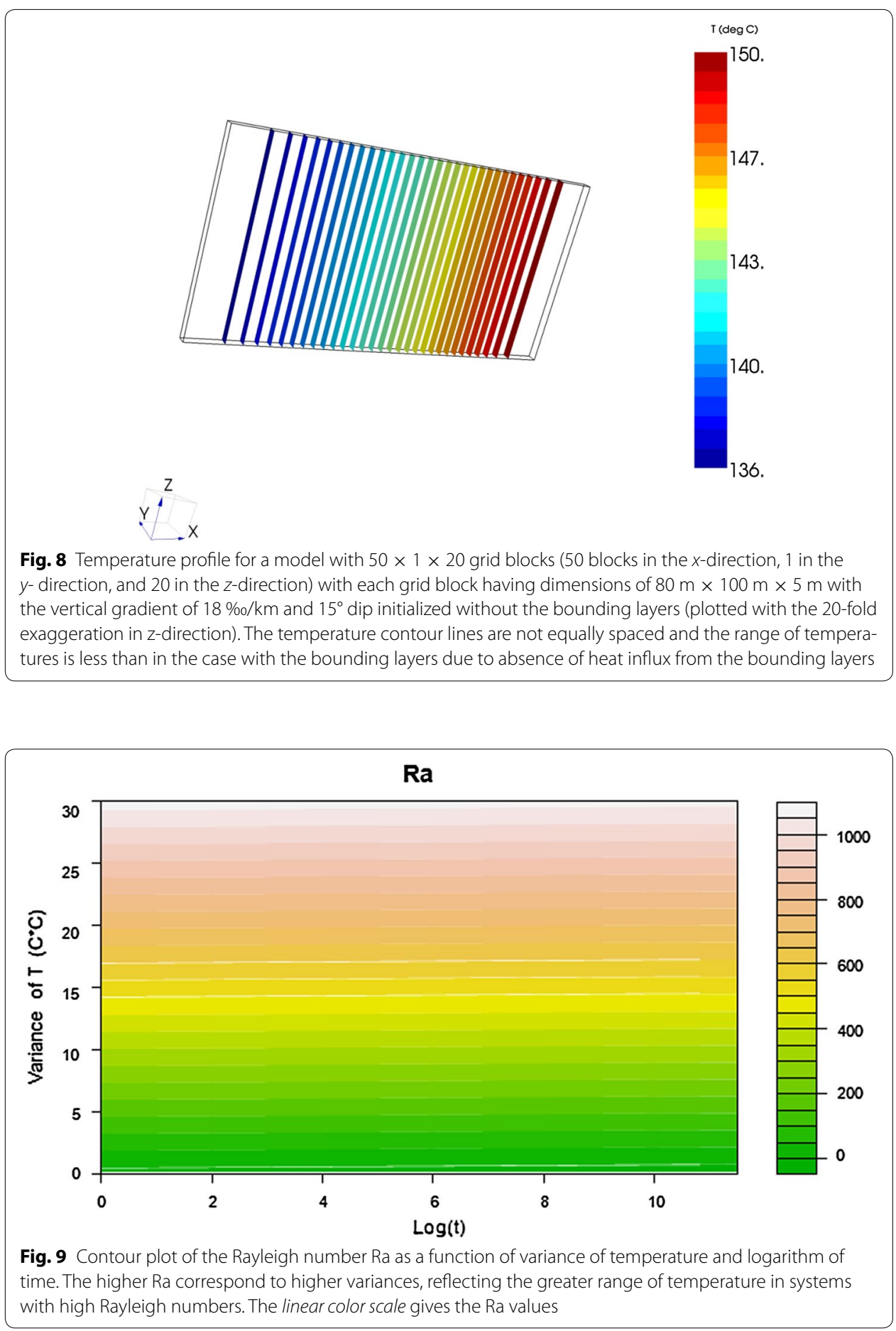

A stepwise regression run and a subsequent ANOVA test show that dip, convection, and their product are the most significant factors:

$$
E=\beta_{0}+\beta_{D} D+\beta_{C} C+\beta_{C D} C D
$$

where $C$ is a boolean variable indicating whether the simulation was run with natural convection initialization, $D$ is dip in degrees, and $E$ is gross energy output in joules; $\beta$ 's 
are the regression coefficients. Even though this model is a result of the analysis that tries to fit all possible combinations of the factors and outputs the best fit, the multiple $\mathrm{R}^{2}$ is relatively low (0.57), indicating poor fit. Nevertheless, an ANOVA test confirms that the two factors identified by the stepwise regression are the most significant (Additional file 1: Appendix C).

Previously, we have established that one factor that affects energy output is initialization with natural convection. A subset of cases initialized without and with natural convection (no $\mathrm{CO}_{2}$ added) was used to compute the difference in energy output, $E$. Prior to the analysis, the expectation was that flat systems would not be significantly affected by initialization. Tilted systems, however, should exhibit increasing difference in energy output. This should occur due to natural convection initialization that causes a wider temperature range and, thus, a higher enthalpy of the produced geofluid. The contour plot (Fig. 10) corroborated the expectation and previous research (Nield and Bejan 2006). Indeed, energy outputs from the systems with zero dips are virtually unaffected by the initialization (Eq. 4). Meanwhile, the upper portion of the contour plot corresponding to high dips shows relative difference in energy outputs from convection and no convection cases of about five percent. The simulation results suggest that cases with significant natural convection always recover more heat.

$$
\Delta E=\frac{2\left(E_{\text {conv }}-E_{n o}\right)}{\left(E_{\text {conv }}+E_{n o}\right)}
$$

Natural convection modeling in this study emphasizes the importance of the bounding layers and the quiescent period. Although the top and bottom bounding layers have the greatest effect on temperature profile in a quiescent system (due to the areal extent of these layers), it would be interesting to investigate the impact of side bounding layers in future research. One potential benefit of modeling a side bounding layer is the ability to incorporate a salt dome with its heat fluxes. However, introduction of additional bounding layers (or heat sources) will impact the duration of the quiescent period. Therefore, a

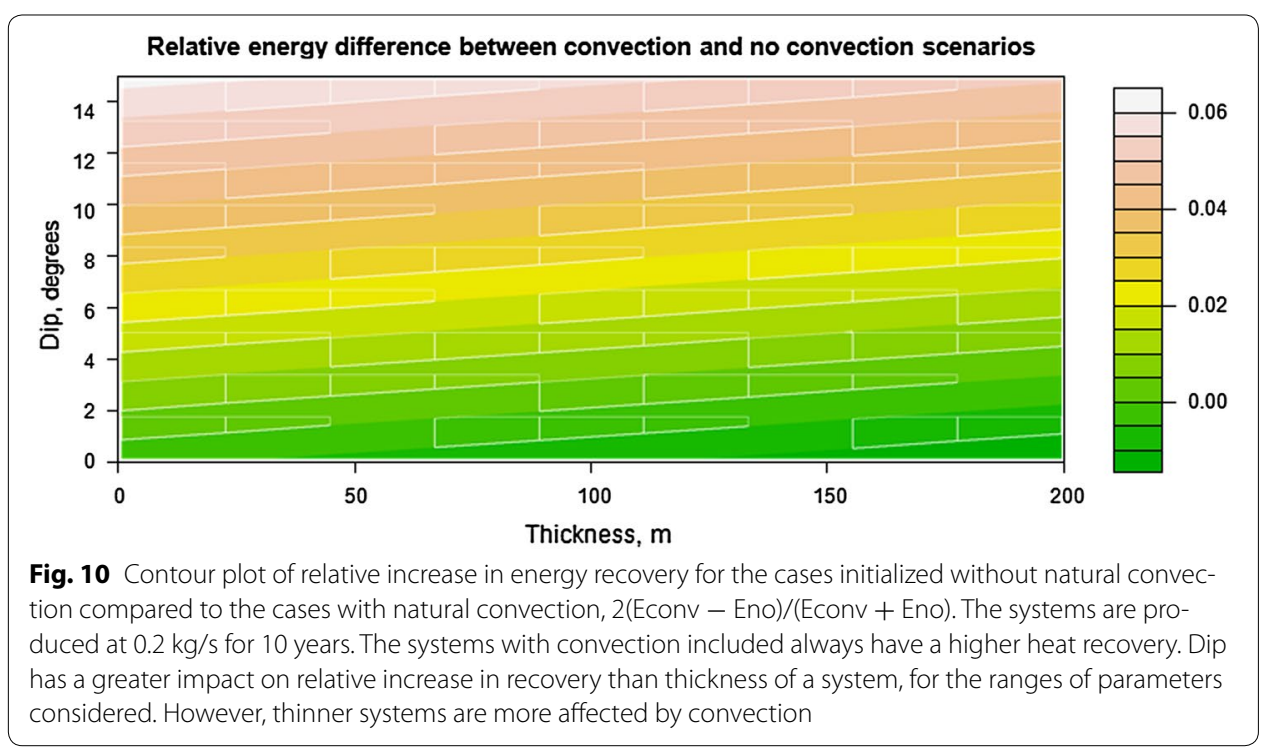


more thorough analysis with a new experimental design might be necessary to establish the time span after which convection in such complex system becomes stable.

In addition to the initialization with natural convection, it is important to establish whether strategic placement of a horizontal $\mathrm{CO}_{2}$ injection well has a positive impact on energy recovery. Based on previous theoretical and experimental research on $\mathrm{CO}_{2}$ sequestration and the fact that the supercritical gas injector can be spatially isolated from the heat extraction well, we expect thermal energy recovery to be comparable or better than in cases without $\mathrm{CO}_{2}$ injection (Farajzadeh et al. 2007; Kneafsey and Pruess 2010). Figure 11 confirms this expectation and demonstrates that differences in energy outputs (analogous to Eq. 4) are small but positive, indicating better performance of the cases with $\mathrm{CO}_{2}$ injection. Here again, cases with higher dip yield higher energy recovery.

\section{Discussion}

Can $\mathrm{CO}_{2}$ sequestration be done simultaneously with heat extraction, without impairing hear recovery? The simulation runs (Fig. 11) show that injection of small amounts of supercritical $\mathrm{CO}_{2}$ away from the geofluid producer and injector is beneficial. Because water displacement (or forced convection) is the dominant component in coupled convection (natural and forced), we conclude that increased energy output in the cases with $\mathrm{CO}_{2}$ injection is due to additional displacement rather than gas dissolution and subsequent density-driven convection. This conclusion, nevertheless, should not undermine further attempts to simultaneously harvest geothermal heat and sequester $\mathrm{CO}_{2}$ with higher injection rates at which the mentioned effects might become more pronounced. The sequestration rate could be increased to match those in major $\mathrm{CO}_{2}$ sequestration projects (NETL 2008). The choice of the low rate of $10^{-4} \mathrm{~kg} / \mathrm{s}$ per meter of the horizontal well was dictated by the necessity to compare against the same production arrangements in different geologic systems (ten-fold difference in permeability, high and zero dips) and does not mean that the rate of $10^{-4} \mathrm{~kg} / \mathrm{s}$ per meter of the horizontal well is the upper limit for each sedimentary geothermal aquifer. For $1000 \mathrm{md}$ permeable and $200 \mathrm{~m}$ thick systems, the $\mathrm{CO}_{2}$ injection rate could have been much higher, but would cause rapid

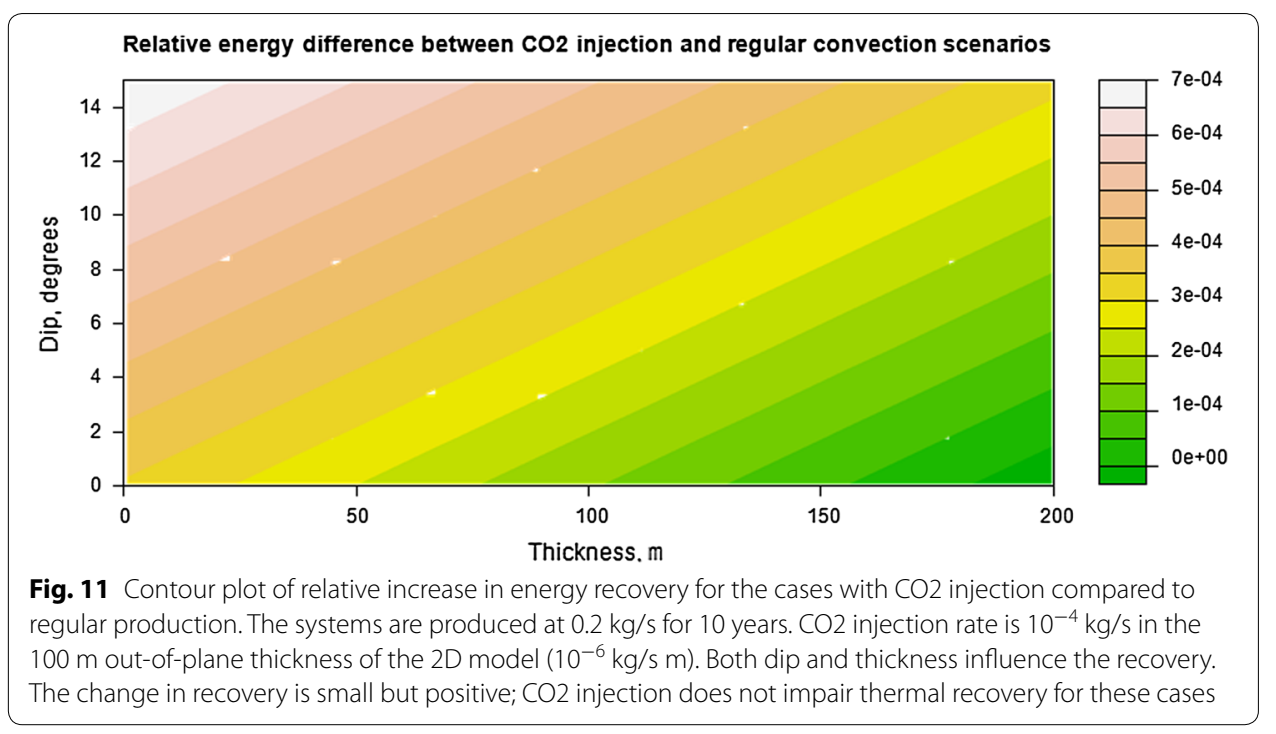


pressure buildup in lower permeability reservoirs (and may lead to stability problems in equation of state). Therefore, the next step in research is to determine whether aquifers with thermodynamic and petrophysical properties favorable for $\mathrm{CO}_{2}$ sequestration can also be prolific geothermal systems.

In addition to these findings, we established that efficient dynamic control over the supercritical gas plume can be established with judicious choice of the locations for both $\mathrm{CO}_{2}$ injection and cold water injection wells. The visual evidence that the supercritical plume has not reached the upper portion of the reservoir and that the injected gas was driven downdip and mixed with the geofluid until very low concentrations is provided in Figs. 12, 13, 14. Figure 12 shows the onset of the rising gas plume after the first year of $\mathrm{CO}_{2}$ injection. At this point, the cold re-injected water from the cold injector well has not reached the rising plume. Figure 13 gives the $\mathrm{CO}_{2}$ concentration surface at the end of the simulation period. As we anticipated, the cold water helped drive the high concentration plume downdip while mixing and dispersing it. The cross-sectional planes of this $\mathrm{CO}_{2}$ concentration surface in Fig. 14 further illustrate that the upper portion of the reservoir has very small concentrations of the supercritical $\mathrm{CO}_{2}$. Thus, it is possible to prevent the uncontrolled rise of the gas plume, ensure caprock integrity, and still produce higher thermal energy output.

\section{Conclusions}

In this study, we conducted a numerical investigation of the effects of the coupled convection and $\mathrm{CO}_{2}$ injection on heat extraction from sedimentary geothermal aquifers. The analysis showed that there were certain benefits in characterizing natural convection pattern prior to heat harvesting, because the knowledge of the convection pattern

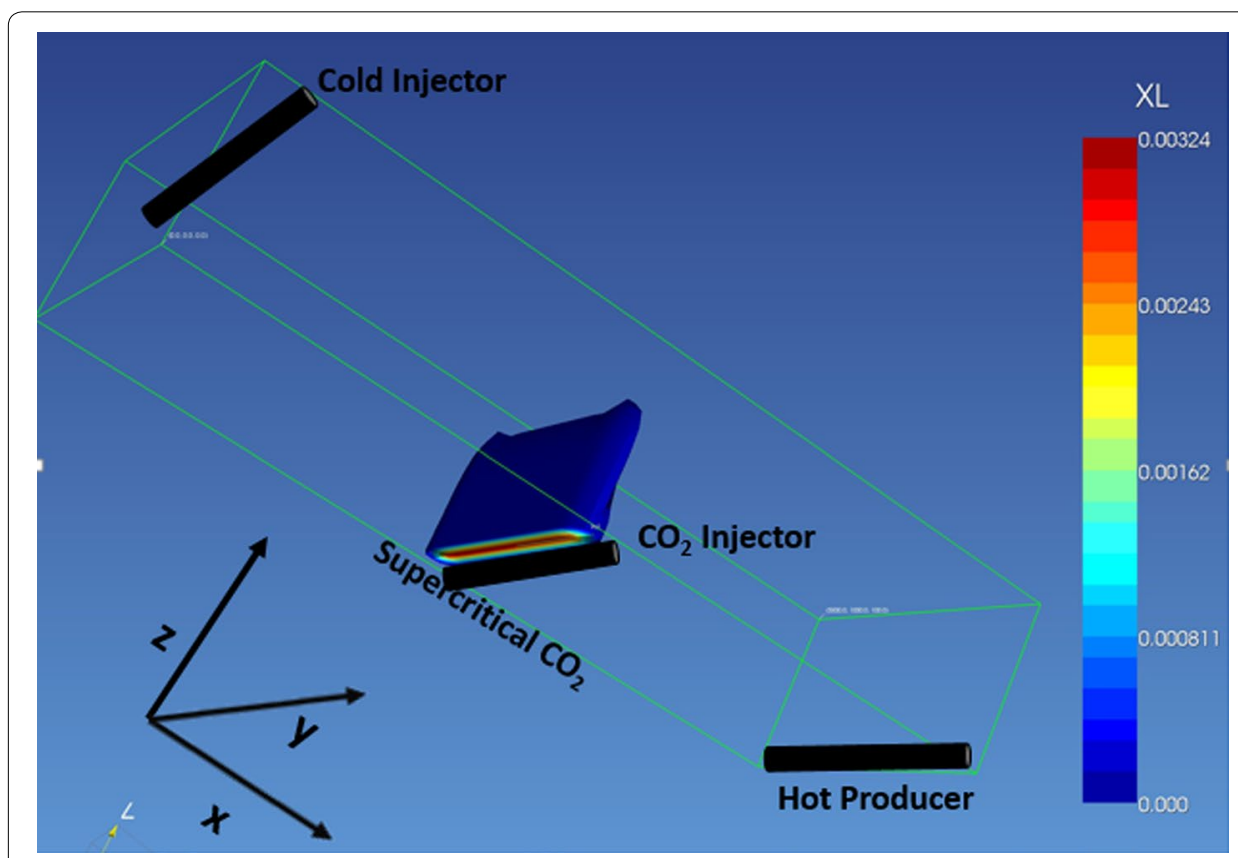

Fig. 12 Fraction of the supercritical $\mathrm{CO}_{2}$ after 1 year of gas injection. The view from the bottom of the reservoir (visualized with PetraSim) 


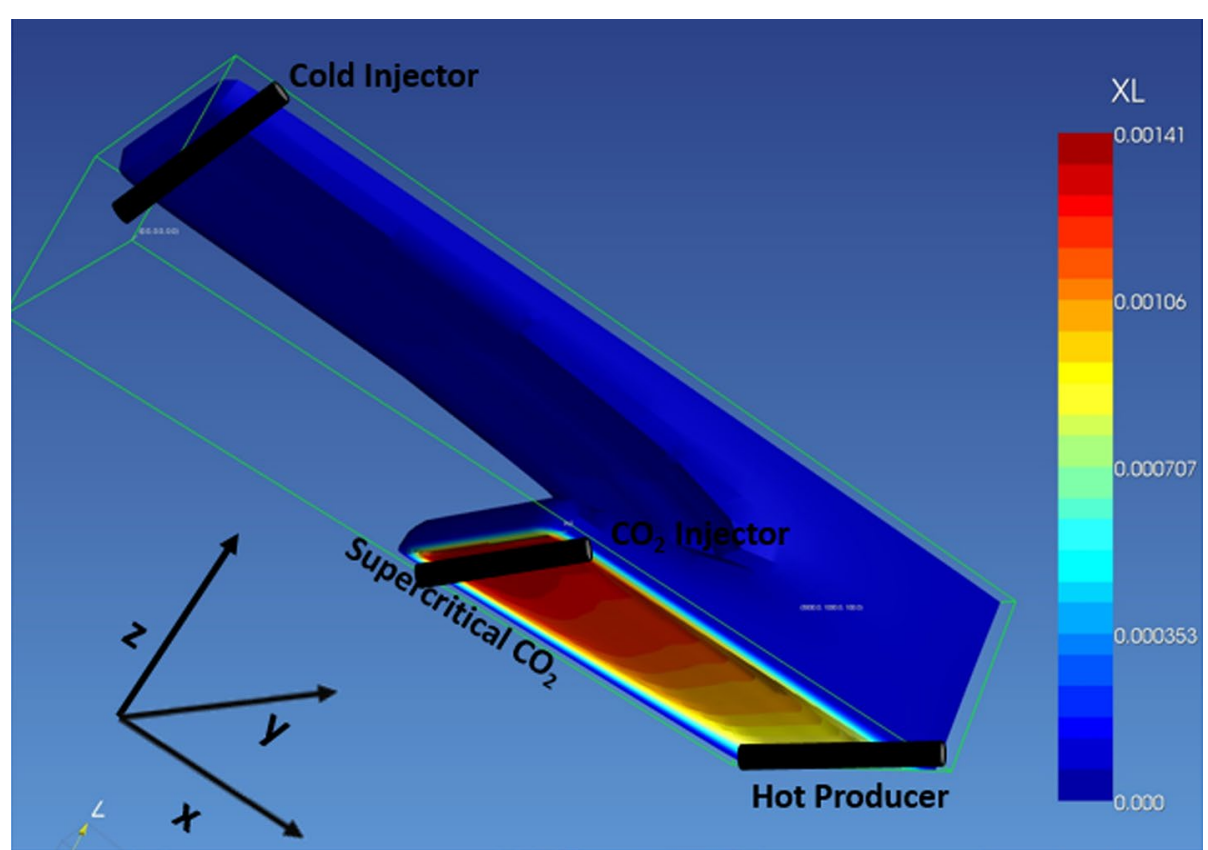

Fig. 13 Fraction of the supercritical $\mathrm{CO}_{2}$ after 20 year of gas injection. The view from the bottom of the reservoir (visualized with PetraSim)

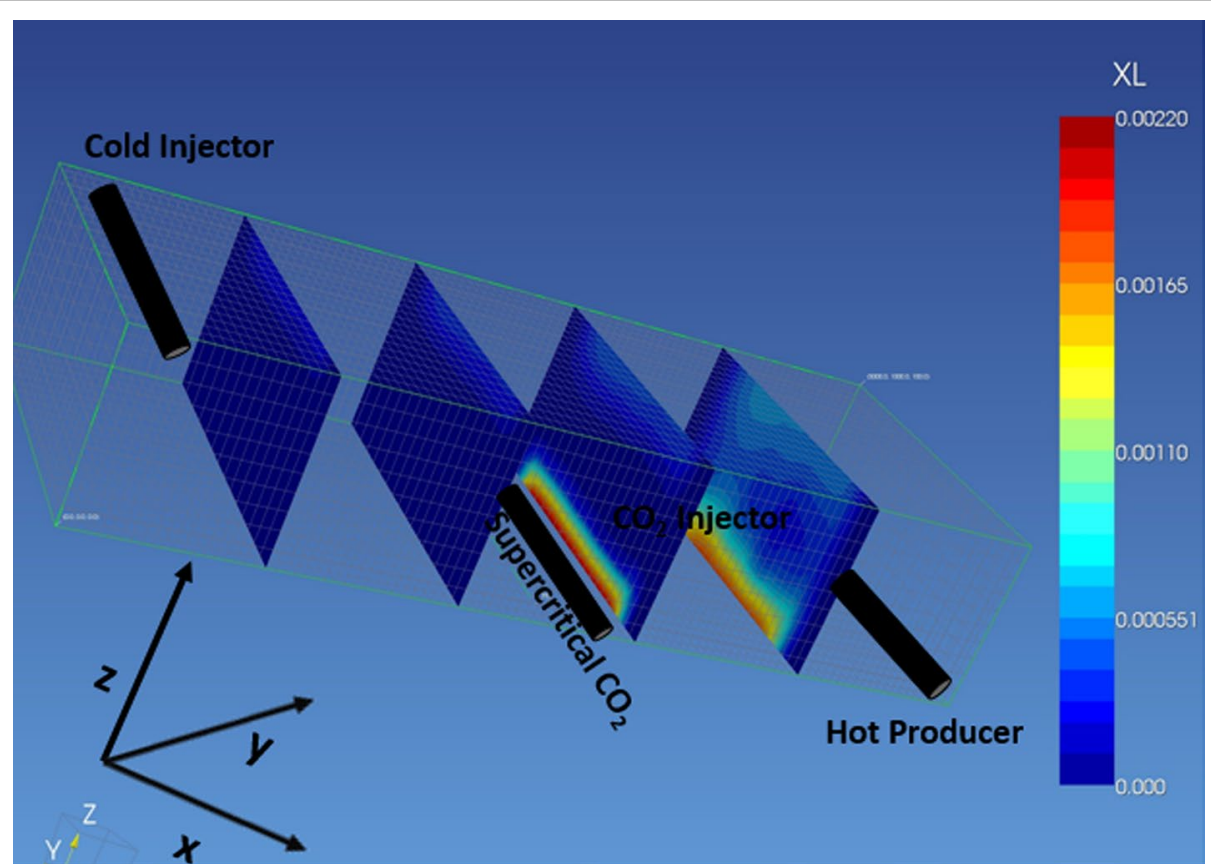

Fig. 14 Fraction of the supercritical $\mathrm{CO}_{2}$ after 20 year of gas injection. The view cross-sectional planes from the side of the reservoir. From the scale it is evident that the plume has been dispersed and only small concentration of the supercritical gas reaches the upper portion of the reservoir (visualized with PetraSim) 
allows to compare meaningfully alternative production designs. Statistical analysis of the simulation results confirmed the expectation that dip controlled the intensity of natural convection and aided forced convection at moderate production and injection rates. The juxtaposition between simulation suites with and without $\mathrm{CO}_{2}$ injection revealed that injection of the supercritical greenhouse gas had a positive impact on the ultimate thermal energy recovery.

This study suggests several interesting directions for future research.

1. $\mathrm{CO}_{2}$ sequestration at higher gas injection rates with simultaneous heat harvesting and dynamic control over the gas plume might further increase revenue. Because both $\mathrm{CO} 2$ sequestration and geothermal aquifer development are marginally profitable, this approach might make the combination project more commercially attractive.

2. A comparative study of alternative software tools might provide calibration of the obtained results and resolution for problems involving heat fluxes. In this study, the analysis of heat fluxes to the wellbore or in and out of the reservoir was used sparingly and qualitatively. The reason for this is limitations imposed by output from TOUGH2 software that does not separate conduction, convection, and radiation. It would be particularly helpful to have such capability for estimation of heat fluxes from bounding layers.

3. One can envision an investigation of effects of non-uniform salinity and heat sources due to the presence of salt domes on the natural convection pattern. Thermohaline convection is an important factor in heat transfer in the GOM coast environment that might have an impact on recovery of geothermal heat.

\section{Additional file}

Additional file 1. Nomenclature, Design of Experiments and Results.

\footnotetext{
Author details

${ }^{1}$ Department of Petroleum Engineering, Texas A\&M University, 907 Richardson Hall, College Station, TX 77843, USA.

${ }^{2}$ Department of Earth and Environmental Sciences, University of Tulane, Room 200 Blessey Hall, New Orleans, LA 70118, USA.
}

\section{Acknowledgements}

Professor Jeffrey Nunn and Tyler Gray (MS) of the Department of Geology and Geophysics, Louisiana State University, characterized the Camerina A reservoir, providing valuable data and guidance. Professor Jeffrey Hanor of the Department of Geology and Geophysics, Louisiana State University, advised on thermohaline flows in the Gulf of Mexico. Financial support for research assistant stipends, travel, training, and computing hardware was provided by the Chevron Distinguished Professorship in the College of Engineering, Louisiana State University. Additional support for purchase of software was provided by the Coast to Cosmos Focus Area at the Center for Computation and Technology, Louisiana State University.

Received: 13 July 2015 Accepted: 7 January 2016

Published online: 21 January 2016

\section{References}

Adams B, Kuehn T, Bielicki J, Randolph J, Saar M. On the importance of the thermosiphon effect in $\mathrm{CPG}_{(\mathrm{CO}}$ plume geothermal) power systems. Energy. 2014;69:409-18.

Anchliya A. Aquifer management for CO2 sequestration. Master's thesis. Texas A\&M University. 2009. 
Curtice R, Dalrymple E. Just the cost of doing business. World Oil. 2004;225(10):77-8.

Esposito A, Augustine C. Geopressured geothermal resource and recoverable energy estimate for the Wilcox and Frio formations, Texas. GRC Transactions. 2011;35:1563-71.

Ewing T, Light P, Tyler N. Thermal and Diagenetic History of the Pleasant Bayou—Chocolate Bayou Area, Brazoria County Texas. Gulf Coast Association of Geological Societies Transactions. 1984;34:341-8.

Farajzadeh R, Salimi H, Zitha P, Bruining J. Numerical simulation of density-driven natural convection in porous media with application for $\mathrm{CO}_{2}$ injection projects. Int J Heat Mass Transf. 2007;50(25-26):5054-64.

Freifeld B, Zakim S, Pan L, Cutright B, Sheu M, Doughty C, Held T. Geothermal energy production coupled with CCS: a field demonstration at the SECARB Cranfield Site, Cranfield, Mississippi, USA. Energy Procedia. 2013;37:6595-603.

Ganjdanesh R, Pope G, Sepehmoori K. Production of energy from saline aquifers: a Method to offset the energy cost of carbon capture and storage. Int J Greenhouse Gas Control. 2015;34:97-105.

Gray T. Geothermal resource assessment of the Gueydan salt dome and the adjacent Southeast Guyedan Field, Vermilion Parish, Louisiana. MS Thesis, Louisiana State University. 2010.

Goodman A, Hakala A, Bromhal G, Deel D, Rodosta T, Frailey S, Small M, Allen D, Romanov V, Fazio J, Huerta N, McIntyre D, Kutchko B, Guthrie G. U.S. DOE methodology for the development of geologic storage potential for carbon dioxide at the national and regional scale. Int J Greenhouse Gas Control. 2011;5:952-65.

Gustavson T, Kreitler C. 1979. An Environmental overview of geopressured-geothermal development: Texas Gulf Coast. Technical report, Bureau of economic geology, The University of Texas at Austin. DOE No. 7949703. http://igor.beg. utexas.edu/readingroom/fulltext.aspx?!D=74077. Accessed 11 Nov 2015.

Hanor J. Kilometer-scale thermohaline overturn of pore fluid in the Louisiana Gulf Coast. Nature. 1987;327:502-3.

Horne R. Transient effects in geothermal convective systems. Dissertation, University of Auckland, New Zealand. 1975.

Islam A, Sharif M, Carlson E. Numerical investigation of double diffusive natural convection of $\mathrm{CO}_{2}$ in a brine saturated geothermal reservoir. Geothermics. 2013;48:101-11.

Karimnezhad M, Jalalifar $\mathrm{H}$, Kamari M. Investigation of caprock integrity for $\mathrm{CO}_{2}$ sequestration in an oil reservoir using numerical method. J Natural Gas Sci Eng. 2014;21:1127-37.

Kneafsey T, Pruess K. Laboratory flow experiments for visualizing carbon dioxide-induced, density-driven brine convection. Transp Porous Media. 2010;82:123-39.

MIT. The future of geothermal energy: impact of enhanced geothermal systems (EGS) on the United States in the 21st century. Technical Report, Renewable Energy and Power Department, Idaho National Laboratory. 2006. https:// mitei.mit.edu/system/files/geothermal-energy-full.pdf. Accessed 13 July 2015.

NETL. Carbon Sequestration Atlas of the United States and Canada. Technical. 2008

Nicot J. Evaluation of large-scale $\mathrm{CO}_{2}$ storage on fresh-water sections of aquifers: an example from the Texas Gulf Coast Basin. Int J Greenhouse Gas Control. 2008:2:582-93.

Nield D, Bejan A. Convection in Porous Media. New York: Springer Science + Business Media Inc; 2006.

Pool M, Carrera J, Vilarrasa V, Silva O, Ayora C. Dynamics and design of systems of injecting dissolved $\mathrm{CO}_{2}$. Adv Water Resour. 2013;62:533-42.

Plaksina T. Modeling effects of coupled convection and $\mathrm{CO}_{2}$ injection in stimulating geopressured geothermal reservoirs. MS thesis, Louisiana State University. 2011.

Pruess K, Oldenburg C, Moridis G. TOUGH2 User's Guide, Version 2.0, Report LBNL-43134, Lawrence Berkeley National Laboratory, Berkeley, Calif. (Superseded by Pruess et al. 2012). 1999.

RTeam. Development core. R: a language and environment for statistical computing. Vienna, Austria: R Foundation for Statistical Computing. 2013. http://web.mit.edu/r_v3.0.1/fullrefman.pdf. Accessed 13 July 2015.

Randolph J, Saar M. Coupling carbon dioxide sequestration with geothermal energy capture in naturally permeable, porous geologic formations: implications for $\mathrm{CO}_{2}$ sequestration. Energy Procedia. 2011;4:2206-13.

Randolph J, Saar M, Bielicki J. Geothermal energy production at geologic $\mathrm{CO}_{2}$ sequestration sites: impact of thermal drawdown on reservoir pressure. Energy Procedia. 2013;37:6625-35.

Salimi H, Wolf K. Integration of heat-energy recovery and carbon sequestration. Int J Greenhouse Gas Control. 2012;6:56-68.

Shukla R, Ranjith P, Haque A, Choi X. A review of studies on $\mathrm{CO}_{2}$ Sequestration and caprock integrity. Fuel. 2010;89:2651-64.

Singh A, Goerke U, Kolditz O. Numerical simulation of non-isothermal compositional gas flow: application to carbon dioxide injection into gas reservoirs. Energy. 2011;36:3446-58.

Smith D, Reeve F. Salt piercement in shallow Gulf Coast salt structures. AAPG Bull. 1970;54(7):1271-89.

Szalkowski S, Hanor J. Spatial variations in the salinity of produced waters from Southwestern Louisiana. GCAGS/ GCSSEPM Transactions. 2003:53:798-806

Vilarrasa V, Silva O, Carrera J, Olivella S. Liquid $\mathrm{CO}_{2}$ injection for geological storage in deep saline aquifers. Int J Greenhouse Gas Control. 2013;14:84-96.

Wang J, Ju Y, Gao F, Liu J. A simple approach for the estimation of $\mathrm{CO}_{2}$ penetration depth into a caprock layer. J Rock Mech Geotechnical Eng. 2015;: doi:10.1016/j.jrmge.2015.10.002.

Warwick P, Verma M, Freeman P, Corum M, Hickman S. US Geological survey carbon sequestration—geologic research and assessment. Energy Procedia. 2014;63:5305-9.

White D, Williams D. Assessment of geothermal resource of the United States. Technical Report, US Geological Survey (USGS) Circular 726. 1975. http://pubs.usgs.gov/circ/1975/0726/report.pdf. Accessed 13 July 2015.

Zhang K, Moridis G, Pruess K. TOUGH $+\mathrm{CO}_{2}$ : a multiphase fluid-flow simulator for $\mathrm{CO}_{2}$ geologic sequestration in saline aquifers. Comput Geosci. 2011;37:714-23.

Zhang L, Ezekiel J, Li D, Pei J, Ren S. Potential assessment of $\mathrm{CO}_{2}$ injection for heat mining and geological storage in geothermal reservoirs of China. Appl Energy. 2014;122:237-46. 